\title{
Evaluation of Fire-Damaged Concrete: An Experimental Analysis based on Destructive and Nondestructive Methods
}

\author{
Gang-Kyu Park'), and Hong Jae Yim ${ }^{2), *}$
}

(Received June 20, 2016, Accepted June 17, 2017, Published online September 12, 2017)

\begin{abstract}
Fire damage to concrete causes contact-type defects that degrade its durability through impaired mechanical properties. Various nondestructive tests are used to evaluate defects induced by fire damage. Recently, nonlinear ultrasonic methods such as the nonlinear resonance vibration method and nonlinear modulation method have been introduced. These nonlinear methods are more sensitive to fire-induced contact-type defects than the linear ultrasonic method. This study involved an experimental analysis of the residual material properties of fire-damaged concrete, specifically, compressive strength, splitting tensile strength, and static elastic modulus. The residual material properties of 116 cylindrical concrete samples with various mix proportions and subjected to various heating temperatures were measured by a destructive method, and their nonlinearity parameters were measured by two nonlinear ultrasonic methods. Through regression analysis, correlated relationships that can facilitate the prediction of residual material properties of fire-damaged concrete using measured nonlinearity parameters were identified. In addition, the effect of fire damage on the mechanical strength of concrete was investigated by comparison with the relationships for undamaged concrete, and relationships for the evaluation of fire-damaged concrete were identified through regression analysis.
\end{abstract}

Keywords: nonlinear ultrasonic method, fire-damaged concrete, mechanical property, correlation study.

\section{Introduction}

Although concrete is popular as a nonflammable material with low thermal conductivity, thermophysical and thermochemical alterations induced in concrete at high temperatures can degrade its performance (Bazant and Kaplan 1996). As the constituent materials of concrete have varying thermal expansion coefficients, fire-damaged concrete has distributed contact-type defects between the individual materials. These defects manifest as openings and pores within the concrete, and the nondestructive assessment of these defects can be used to evaluate the extent of fire damage (Yim et al. 2014). Researchers have conducted experimental studies to identify the effect of fire damage on the material properties of concrete with various mix proportions under various fire scenarios (Chang et al. 2006; Handoo et al. 2002; Lee et al. 2008; Tufail et al. 2016). It has been reported that high temperatures degrade the material properties of concrete,

\footnotetext{
${ }^{1)}$ Department of Civil and Environmental Engineering, Korea Advanced Institute of Science and Technology, 291 Daehak-ro, Yuseong-gu, Daejeon 34141, Republic of Korea.

${ }^{2)}$ Department of Construction and Disaster Prevention Engineering, Kyungpook National University, 2559 Gyeongsang-daero, Sangju, Gyeongsangbuk-do 742-711, Republic of Korea.

*Corresponding Author; E-mail: yimhj@knu.ac.kr Copyright (c) The Author(s) 2017. This article is an open access publication
}

including strength (Al-Nimry and Ghanem 2017; Dos Santos et al. 2002; Li and Liu 2016). To evaluate the durability and reusability of fire-damaged concrete, destructive and nondestructive tests are performed in this study with various proposed methods.

An increase in contact-type defects within fire-damaged concrete results in the degradation of mechanical properties including stiffness and strength. Among the nondestructive methods, ultrasonic measurement methods demonstrate high potential and are applicable for evaluating damaged concrete (Dilek 2007; Dilek and Leming 2007; Ham and Oh 2013). These methods can be divided into two categories depending on the measurement techniques and target defects: linear and nonlinear ultrasonic methods. Linear ultrasonic methods, which measure wave velocity, wave attenuation, and impact echo, are conventional ultrasonic methods and have been widely used to evaluate damaged concrete, particularly firedamaged concrete (Chaix et al. 2003; Colombo and Felicetti 2007; Dilek and Leming 2007; Epasto et al. 2010; Kee and Nam 2015; Yang et al. 2009). However, these linear methods exhibit lower sensitivity to distributed defects and contacttype defects at the micro-scale (Jhang 2009; Park et al. 2015) compared to nonlinear ultrasonic methods, which are more sensitive to early-stage micro-scale defects as these defects cause nonlinear behavior of an incident wave (Zaitsev et al. 2006). To investigate this phenomenon in concrete, Chen et al. (2010) performed an experiment to characterize microscale defects induced by an alkali-silica reaction by using a nonlinear impact resonance acoustic spectroscopy technique. In addition, Payan et al. (2007) conducted nonlinear resonant 
ultrasound spectroscopy to assess the damage to concrete caused by exposure to high temperatures. Moreover, recently, defects in fire-damaged concrete with various mix proportions and under various temperature scenarios have been evaluated by various nonlinear ultrasonic methods (Park et al. 2015; Yim et al. 2014).

Park et al. (2015) measured the hysteretic nonlinearity parameter (HNP) of fire-damaged concrete with various mix proportions and under various fire scenarios by using a nonlinear resonance vibration method (Van Den Abeele et al. 2000a). The splitting tensile strengths of the samples were also evaluated, and the correlation between both the measurement results was reported. On the other hand, Yim et al. (2014) measured the nonlinearity parameters of concrete samples fabricated with mix proportions same as to those in a previously mentioned study, using a nonlinear modulation method (Van Den Abeele et al. 2000b). Moreover, measurements of residual material properties such as compressive strength, static elastic modulus, and peak strain were also performed to obtain correlations with the nonlinear parameter. Notwithstanding the numerous correlation studies of fire-damaged concrete that have been reported to date, several correlations remain to be analyzed. In this context, the present study involves an experimental analysis to evaluate the residual material properties of fire-damaged concrete based on nonlinearity parameters measured using two dissimilar nonlinear ultrasonic methods. To examine the sensitivity of the two nonlinear ultrasound methods in evaluating fire-damaged concrete of various mix proportions at various temperatures, their results are compared, and correlated relationships are proposed to assess residual mechanical strengths using measured nonlinearity parameters. In addition, the relationship between the compressive strength and tensile strength of fire-damaged concrete is proposed and compared with the corresponding relationships for undamaged concrete.

\section{Sample Preparation: Fire-Damaged Concrete}

Four types of concrete samples were prepared for destructive and nondestructive tests after fire damage. Each type of concrete sample had a unique mix proportion regulated by varying the water-to-cement weight ratios $(w / \mathrm{cm})$ and fine-to-coarse aggregate weight ratios for normal strength concrete. Type I Portland cement was used to produce all the samples with crushed gravel as coarse aggregate (maximum size $19 \mathrm{~mm}$ ) and fine aggregate (maximum size $4 \mathrm{~mm}$ ). Additional admixtures or materials were not used in any of the concrete samples. According to the various mix proportions, the samples were labeled from $\mathrm{C} 1$ to $\mathrm{C} 4$, as presented in Table 1. The concrete samples were cast into a cylindrical shape with a height of $200 \mathrm{~mm}$ and diameter of $100 \mathrm{~mm}$. Totally, 116 cylindrical concrete samples (29 samples for each mix) were then cast and cured for 28 days prior to high temperature exposure.
For measurements using the nonlinear modulation method and compressive strength test, 16 cylindrical samples, including four reference specimens, were used for each mix. On the other hand, for the nonlinear resonance vibration method and splitting tensile strength test, 13 cylindrical samples, including one reference specimen, were used for each mix. Moreover, each cylindrical sample was divided into five disk samples that were $25 \mathrm{~mm}$ in height.

Prior to exposure to high temperatures, the prepared concrete samples were placed in a drying oven at $100{ }^{\circ} \mathrm{C}$ for approximately $24 \mathrm{~h}$ to avoid hygrothermal spalling, i.e., explosive spalling, during the fire experiment. The concrete samples, apart from the reference samples, were then exposed to various peak temperatures (200, 400, and $600{ }^{\circ} \mathrm{C}$ ). For the homogenization of temperature in the entire volume of each sample, exposure to peak temperatures was maintained for $2 \mathrm{~h}$ using an electric muffle furnace as it was reported that heat conduction up to the center of a sample is complete when it is subjected to $2 \mathrm{~h}$ of exposure (Yim et al. 2014). After exposure, all the samples were cooled in water at $20{ }^{\circ} \mathrm{C}$ for $5 \mathrm{~min}$ to avoid unexpected recovery phenomena during cooling, such as refilling of the fire-induced defects due to rehydration under a high-humidity condition, and were subsequently kept under an air-curing condition.

The degree of thermal damage in fire-damaged concrete is influenced by several factors including exposure temperature, exposure time, after-fire curing periods, and sample sizes. Among these factors, it has been reported that the after-fire curing period insignificantly affects the residual material properties under an air-cured condition, while firedamaged concrete under a completely saturated curing condition appears to recover its mechanical strength (Park et al. 2015). Accordingly, for a correlation analysis, the concrete samples in this study were air-cured after heating to ignore the curing condition. Additionally, sample size influences the degree of thermal damage; however, it has been reported that varying the sample size negligibly influences the measured nonlinearity parameters (Yim et al. 2014). Therefore, this study attempts to correlate the measured HNP of thin disk samples with the measured nonlinearity parameter of the cylindrical samples.

\section{Nonlinear Ultrasonic Methods}

\subsection{Nonlinear Resonance Vibration Measurement}

The nonlinear resonance vibration method is a nonlinear ultrasonic technique based on the measurement of the resonance frequency shift. This implies that it measures the frequency variation between the input and output signals, which is a function of the degree of damage. This can be described by the phenomenological model for hysteretic nonlinearity proposed by Van den Abeele et al. (2000a). The constitutive relationship for the elastic modulus $K$ can be expressed as follows (Van Den Abeele et al. 2000a): 
Table 1 Mix proportions of concrete samples.

\begin{tabular}{c|c|c|c|c|c|c}
\hline Mix & Water $\left(\mathrm{kg} / \mathrm{m}^{3}\right)$ & Cement $\left(\mathrm{kg} / \mathrm{m}^{3}\right)$ & $\begin{array}{c}w / \mathrm{cm} \\
\text { ratio }\end{array}$ & $\begin{array}{c}\text { Fine aggregate } \\
\left(\mathrm{kg} / \mathrm{m}^{3}\right)\end{array}$ & $\begin{array}{c}\text { Coarse aggregate } \\
\left(\mathrm{kg} / \mathrm{m}^{3}\right)\end{array}$ & $\begin{array}{c}\text { Fine-to-coarse } \\
\text { aggregate ratio }\end{array}$ \\
\hline \hline $\mathrm{C} 1$ & 160 & 320 & 0.5 & 744 & 1100 & 0.68 \\
\hline $\mathrm{C} 2$ & 171 & 285 & 0.6 & 744 & 1100 & 0.68 \\
\hline $\mathrm{C} 3$ & 160 & 320 & 0.5 & 922 & 922 & 1 \\
\hline $\mathrm{C} 4$ & 171 & 285 & 0.6 & 922 & 922 & 1 \\
\hline
\end{tabular}

$$
K(\varepsilon, \dot{\varepsilon})=K_{0}\{1-\alpha[\Delta \varepsilon+\varepsilon(t) \operatorname{sign}(\dot{\varepsilon})+\cdots\}
$$

where $\alpha$ is the HNP, $\dot{\varepsilon}$ is the strain rate, $\Delta \varepsilon$ is the strain amplitude variation over the previous period, and $\operatorname{sign}(\dot{\varepsilon})=$ 1 if $\dot{\varepsilon}>0$ or $\operatorname{sign}(\dot{\varepsilon})=-1$ if $\dot{\varepsilon}<0$. The hysteretic nonlinearity of cement-based materials can be measured by the hysteretic nonlinear characteristics, namely nonlinear attenuation, harmonic generation, and amplitude-dependent resonance frequency shift, which are sensitive to contacttype defects. Therefore, these characteristics have been used as damage indicators (Chen et al. 2011; Leśnicki et al. 2011; Van Den Abeele et al. 2000a). Park et al. (2015) measured the HNP to evaluate the degree of fire damage by using the amplitude-dependent resonance frequency shift. The resonance frequency shift with variation in the input amplitude can be expressed as follows (Van Den Abeele et al. 2000a):

$$
\frac{f_{0}-f}{f_{0}}=\alpha \Delta \varepsilon
$$

where $f_{0}$ is the linear resonance frequency, and $f$ is the measured resonance frequency according to the magnitude of the input amplitude. Moreover, $\operatorname{HNP}(\alpha$ : obtained from the amplitude-dependent resonance frequency shift) can be used as the damage factor. The resonance frequency varies linearly with increasing input amplitude, and the degree of shift increases with damage. Therefore, the extent of fire damage can be evaluated through an analysis of the amplitude-dependent resonance frequency shift; further details are available in the study by Van Den Abeele et al. (2000a).

For an experiment based on this relationship, thin, diskshaped concrete samples ( $25 \mathrm{~mm}$ in height) were prepared and placed on a soft mat, which provides a soft boundary condition that maximizes the capability of the disks for free vibration and minimizes noise from the external experimental conditions. The experimental setup is illustrated in Fig. 1. To generate impact excitation in the sample, a steel bead (diameter $15 \mathrm{~mm}, 13.8 \mathrm{~g}$ ) was dropped 20 times from various heights onto the center of the sample; the intensity of impact of the steel bead is to be unique for each attempt to obtain the amplitude-dependent resonance frequency shift. The vibration response induced by an impact was measured by a shear piezoelectric accelerometer (PCB 353B15, PCB Piezotronics Inc.) attached on the opposite side of the sample. Through an analog-to-digital converter (NI PXI 4472-B,
National Instruments Corp.), the analog response signal was converted to a digital signal with a sampling rate of $100 \mathrm{kHz}$ and duration of $50 \mathrm{~ms}$. The vibration signal was then converted to the frequency domain via fast Fourier transform (FFT); a representative vibration signal and the corresponding FFT result are presented in Fig. 2. The linear resonance frequency $\left(f_{0}\right)$ is determined by linear regression analysis, as the $\mathrm{x}$-axis intercept of the FFT result. This is because the linear resonance frequency, which is dependent on the amplitude, is challenging to obtain by an impact test. The HNP is then determined by measuring the amount of resonance frequency shift according to the intensity of impact based on the linear resonance frequency; further details regarding the experimental procedure are available in the study by Park et al. (2015).

\subsection{Nonlinear Modulation Measurement}

The constitutive law of concrete materials follows a nonlinear behavior and is expressed up to second-order nonlinearity in a straightforward manner as follows (Van Den Abeele 1996; Van Den Abeele et al. 2000b):

$$
\sigma=E_{0} \varepsilon(1+\beta \varepsilon)
$$

where $\sigma$ is the stress, $E_{0}$ is the Young's modulus, $\varepsilon$ is the strain, and $\beta$ is the second-order nonlinear coefficient. Nonlinear ultrasonic phenomena such as higher harmonics mode or mixed frequency response are represented by wave propagation through a solid medium (Payan et al. 2010; Van Den Abeele et al. 2000b). The mixed frequency response can be obtained using two types of generating waves with unequal frequencies and nonlinear wave modulation spectroscopy. A low-frequency vibration $\left(f_{l}\right)$ and a high-frequency stress wave $\left(f_{h}\right)$ are generated by the shaker and ultrasonic transducer, respectively. When simultaneously applying both low and high frequencies to a sample, the lowfrequency wave causes modulation of the high-frequency wave at the contact-type defects in the sample. This results in an additional spectrum of the modulated wave at the sideband range in the frequency domain. The sideband is generally located at the sum and difference of both frequencies $\left(f_{l} \pm f_{h}\right)$, and the spectral component of the modulated frequency can represent the nonlinear behavior induced by contact-type defects.

The amplitude of the sideband is proportional to the amplitude of the low- and high-frequency generated signals 


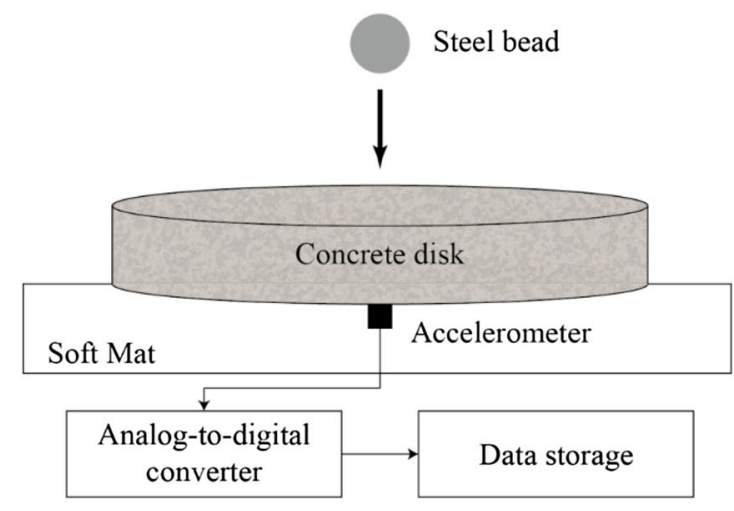

(a)

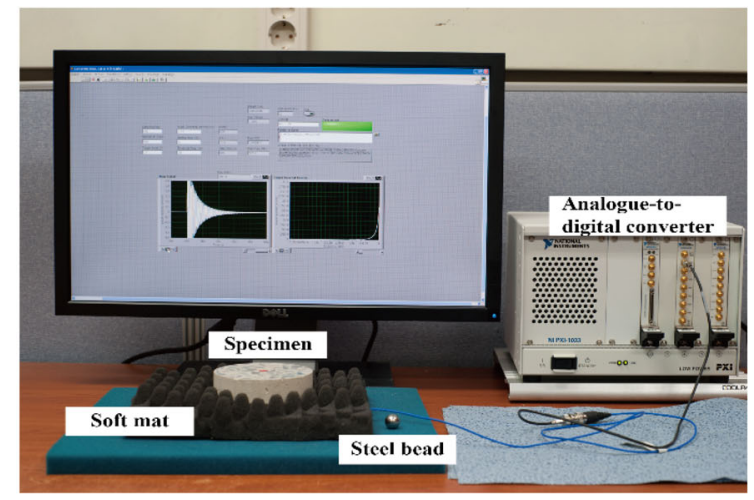

(b)

Fig. 1 Experimental setup of nonlinear resonance vibration method. a Schematic of experimental system and b experimental setup.

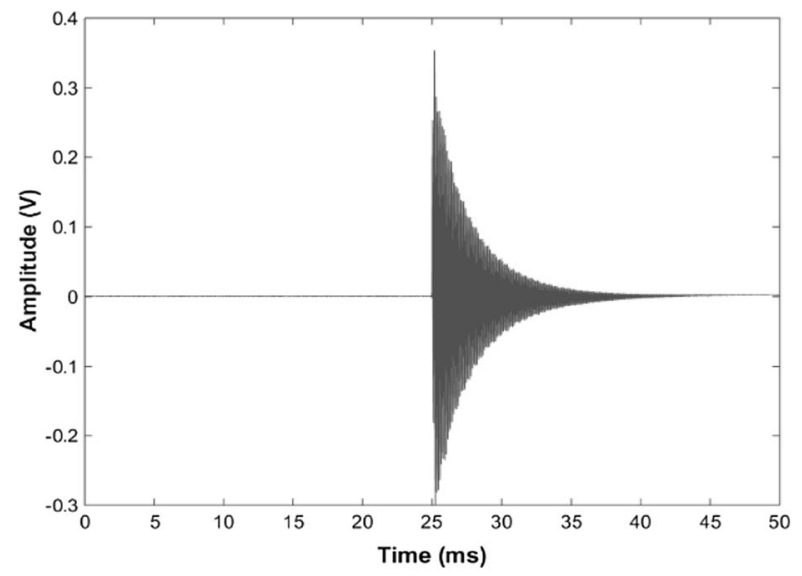

(a)

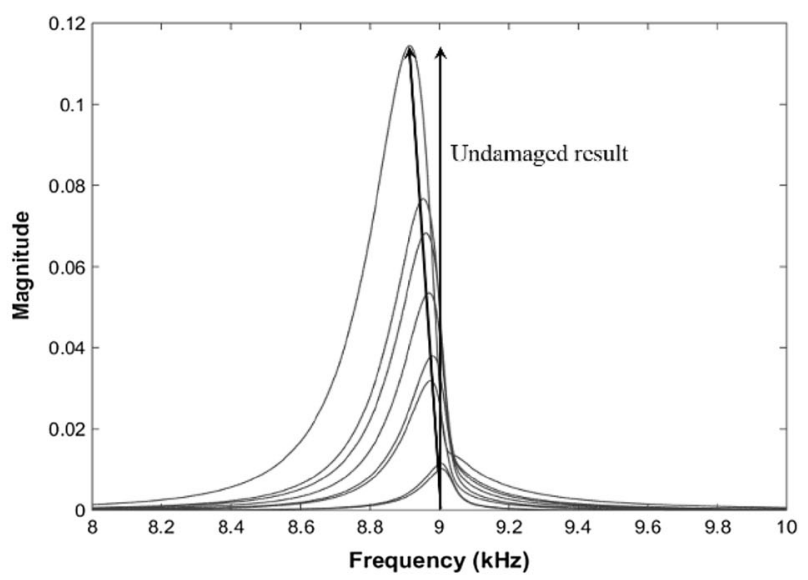

(b)

Fig. 2 Representative results of vibration signal and the amplitude-dependent resonance frequency shift of damaged concrete. a Vibration signal and b FFT.

and the area of contact-type defects in the sample (Donskoy et al. 2001). This implies that the nonlinearity parameter $(D)$ can be evaluated by the energy relationship of both high $\left(P_{h}\right)$ and low frequencies $\left(P_{l}\right)$ and the sideband component $\left(P_{s}\right)$. Accordingly, the nonlinearity parameter that reflects the degree of contact-type defects in the sample can be obtained by the following expression (Van Den Abeele et al. 2000b; Warnemuende and $\mathrm{Wu} 2004)$ :

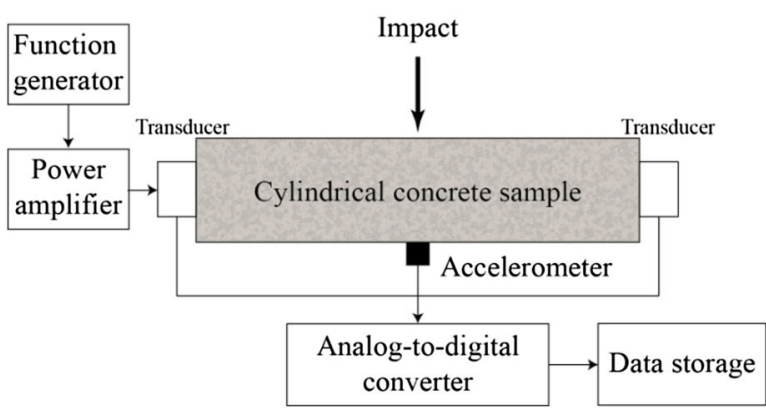

(a)

$$
\frac{P_{s}}{P_{h}}=D P_{l}
$$

Yim et al. (2014) proposed an impact-modulation method to identify the degree of thermal damage to concrete. The experimental setup of this method is illustrated in Fig. 3. A low-frequency vibration $\left(f_{0}\right)$, instead of a low-frequency ultrasonic longitudinal wave, was generated using an impact

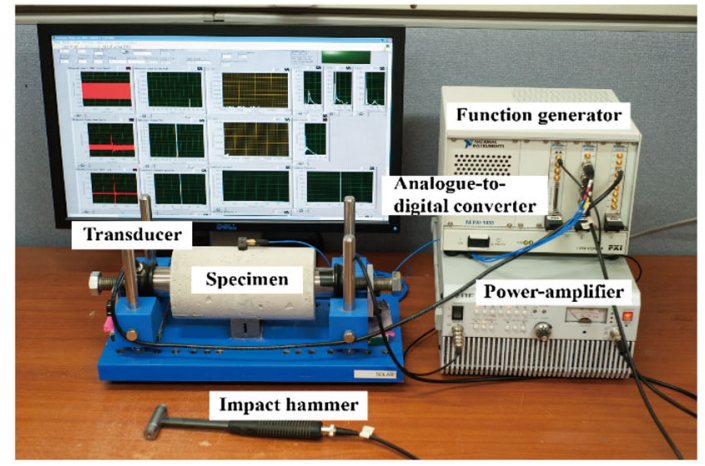

(b)

Fig. 3 Experimental setup of nonlinear modulation method. a Schematic of experimental system and $\mathbf{b}$ experimental setup. 
hammer with a soft tip (086C03; PCB Piezotronics, Inc.) to create a resonance vibration mode in the sample (Donskoy et al. 2001; Warnemuende and Wu 2004). High-frequency sinusoidal signals were generated using a function generator (NI PXI-5421; National Instruments Corp.) with a sample rate of $100 \mathrm{MS} / \mathrm{s}$, and a power amplifier (BA4825; NF Corp.) was used to amplify the generated signal. Two longitudinal narrow-band transducers (Panametrics X1019; Olympus NDT, Inc.) with a center frequency of $46.1 \mathrm{kHz}$ were used for transmitting and receiving the high-frequency ultrasonic wave passing through the sample, and a tri-axial accelerometer (356A33; PCB Piezotronics, Inc.) placed opposite to the impact region measured the impact vibration (low frequency) in the three orthogonal directions. The measured high-frequency signal was digitized (NI PXI5105; National Instruments Corp.) with a $60 \mathrm{MS} / \mathrm{s}$ sampling rate (12 bit resolution), and the dynamic vibration was measured (NI PXI-4472B; National Instruments Corp.) with a sampling rate of $102.4 \mathrm{kS} / \mathrm{s}$ (24 bit resolution).

The spectral energy of the impact vibration $\left(E_{l}\right)$ was determined by the integrated power spectral density of the measured signal of frequency up to $5 \mathrm{kHz}$. The spectral energy of the sideband was obtained by integrating the power spectral density of the ultrasonic signal of frequency between 41.1 and $51.5 \mathrm{kHz}$, excluding the range of the highfrequency waves $(46.1 \mathrm{kHz})$. The nonlinearity parameter was then obtained from the slope of the relationship between the modulated energy $\left(E_{s} / E_{h}\right)$ and the impact vibration $\left(E_{l}\right)$. Thirty measurements per test for each sample were conducted at an identical position to obtain a linear curve, and ten independent tests were performed for reproducibility at other arbitrary locations of impact and accelerometer placement. The representative results of frequency modulation achieved by simultaneously applying the low and high frequency waves are presented in Fig. 4. The nonlinearity parameter can then be obtained from the average of the values from the 10 tests. It has been reported that the ratio of increase of the nonlinearity parameter represents contacttype defects developed because of thermal damage to the concrete. A detailed description of the phenomena related to this experiment is available in the study by Yim et al. (2014).

\section{Mechanical Strength Measurements}

After obtaining the fire damage and nondestructive measurements of the fabricated concrete samples, two types of mechanical strength measurements were performed. The thin-disk samples were used to obtain the splitting tensile strength according to the degree of fire damage. Based on the measured dimensions and mass of the samples, the splitting tensile strength test was performed following the procedure of ASTM C 496 (2011). As illustrated in Fig. 5, the concrete sample was placed in the direction of the diameter at the center of the bearing plates, and two wood straps were placed between the bearing plates and the sample to avoid interface cracking and to apply a distributed load along the length of the disks. The splitting tensile strength can then be obtained by the following expression:

$$
T_{s}=\frac{2 F}{\pi l d}
$$

where $T_{S}$ is the splitting tensile strength, $F$ is the maximum applied load until failure of each sample, and $l$ and $d$ are the length and diameter of the sample, respectively. Park et al. (2015) reported that the measured tensile strength decreased with increasing fire damage to the concrete sample. Following ASTM C39 (2001), the compressive strength was also obtained using cylindrical concrete samples subjected to varying degrees of fire damage, and the axial deformation and uniaxial stress-strain curve were measured using displacement transducers attached on the sides of the cylinder. From this experiment, Yim et al. (2014) measured the residual mechanical properties of fire-damaged concrete, such as compressive strength, static elastic modulus (calculated as the secant elastic modulus), and peak strain, with respect to the degree of thermal damage. The reported results indicated that increasing the fire damage to concrete

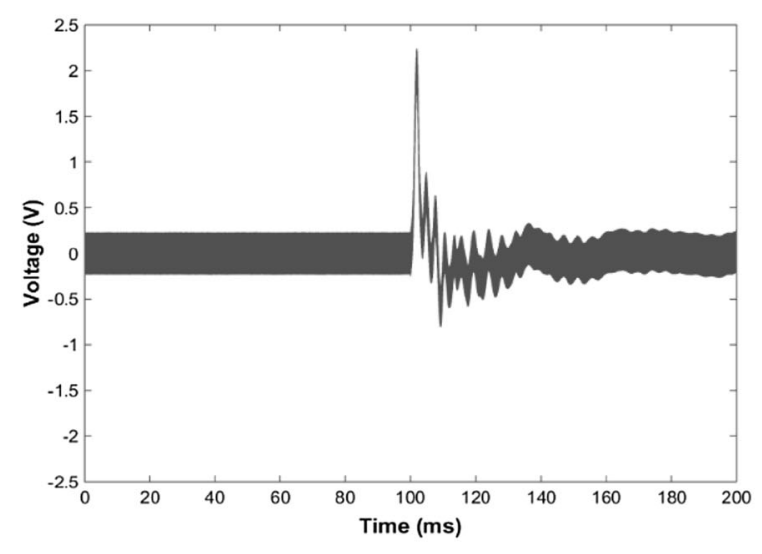

(a)

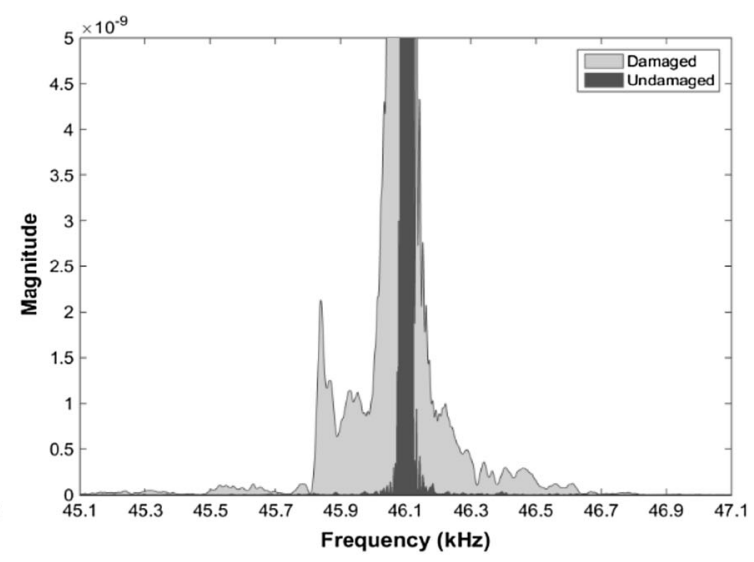

(b)

Fig. 4 The modulated high frequency wave of samples. a Modulation signal in time domain and b frequency spectra. 


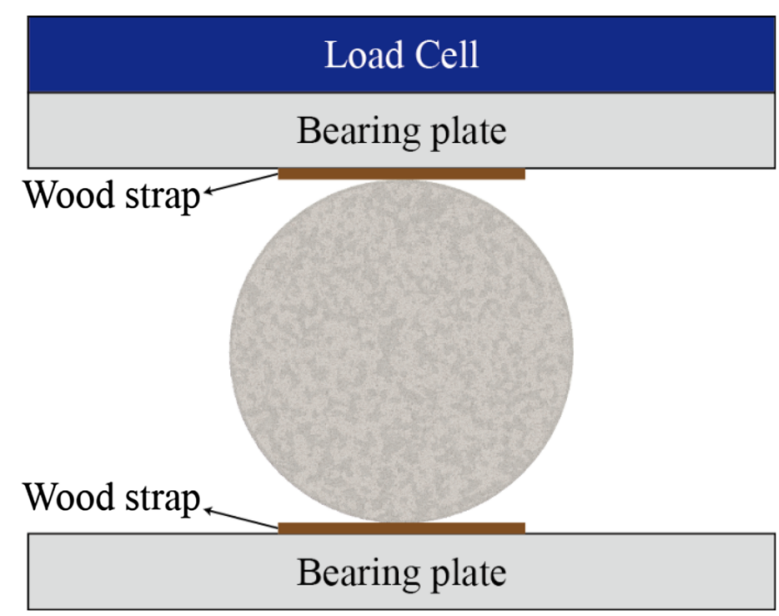

(a)

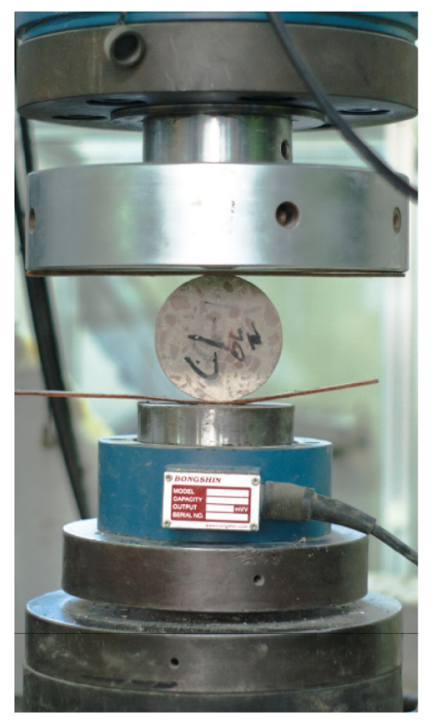

(b)

Fig. 5 Schematic diagram of splitting tensile strength test. a Schematic diagram and b experimental setup (Park et al. 2015).

degrades the mechanical properties and induces a linear stress-strain curve.

\section{Results and Discussion}

Based on previous studies (Park et al. 2015; Yim et al. 2014), this study performed an experimental analysis using selected parameters of mechanical strength (compressive and tensile strength) and measured nonlinearity parameters (HNP and nonlinearity parameter); the initial and post-fire-damage material properties are presented in Table 2. Figure 6 presents the increased ratios of the nonlinearity parameters as measured by the two methods with various mix proportions and under various heating temperatures; the results were calculated as the ratio of the increase to the reference result $\left(20{ }^{\circ} \mathrm{C}\right)$. To ascertain their experimental adequacy, the sensitivity of the two nonlinearity parameters, as measured by the nonlinear resonance vibration method and nonlinear modulation method, were analyzed by comparing the results.

Table 2 The average results of destructive and non-destructive tests.

\begin{tabular}{|c|c|c|c|c|c|c|}
\hline Mix & Temp. & $\begin{array}{c}\text { Compressive } \\
\text { strength (MPa) }\end{array}$ & $\begin{array}{l}\text { Splitting tensile } \\
\text { strength (MPa) }\end{array}$ & $\begin{array}{l}\text { Secant elastic } \\
\text { modulus }\end{array}$ & HNP & $\begin{array}{c}\text { Nonlinearity } \\
\text { parameter (D) }\end{array}$ \\
\hline \multirow[t]{4}{*}{$\mathrm{C} 1$} & Initial $\left(20^{\circ} \mathrm{C}\right)$ & 52.11 & 4.33 & 33.25 & $1.82\left(10^{-6}\right)$ & 0.046 \\
\hline & $200^{\circ} \mathrm{C}$ & 37.17 & 3.96 & 22.89 & $5.98\left(10^{-6}\right)$ & 0.225 \\
\hline & $400^{\circ} \mathrm{C}$ & 30.37 & 2.59 & 8.169 & $1.12\left(10^{-5}\right)$ & 4.645 \\
\hline & $600^{\circ} \mathrm{C}$ & 23.96 & 1.00 & 2.911 & $2.84\left(10^{-5}\right)$ & 21.25 \\
\hline \multirow[t]{4}{*}{$\mathrm{C} 2$} & Initial $\left(20^{\circ} \mathrm{C}\right)$ & 39.03 & 3.56 & 28.61 & $9.02\left(10^{-7}\right)$ & 0.022 \\
\hline & $200{ }^{\circ} \mathrm{C}$ & 27.08 & 3.34 & 18.74 & $4.73\left(10^{-6}\right)$ & 0.240 \\
\hline & $400^{\circ} \mathrm{C}$ & 25.67 & 2.15 & 6.651 & $1.54\left(10^{-5}\right)$ & 3.093 \\
\hline & $600^{\circ} \mathrm{C}$ & 18.29 & 0.84 & 2.154 & $2.97\left(10^{-5}\right)$ & 20.536 \\
\hline \multirow[t]{4}{*}{$\mathrm{C} 3$} & Initial $\left(20^{\circ} \mathrm{C}\right)$ & 46.71 & 4.11 & 30.82 & $7.68\left(10^{-7}\right)$ & 0.030 \\
\hline & $200^{\circ} \mathrm{C}$ & 34.78 & 3.62 & 18.88 & $4.30\left(10^{-6}\right)$ & 0.224 \\
\hline & $400^{\circ} \mathrm{C}$ & 27.68 & 2.46 & 7.190 & $1.15\left(10^{-5}\right)$ & 2.330 \\
\hline & $600^{\circ} \mathrm{C}$ & 21.81 & 1.07 & 3.002 & $2.04\left(10^{-5}\right)$ & 14.26 \\
\hline \multirow[t]{4}{*}{$\mathrm{C} 4$} & Initial $\left(20^{\circ} \mathrm{C}\right)$ & 38.70 & 3.78 & 27.32 & $6.82\left(10^{-7}\right)$ & 0.021 \\
\hline & $200^{\circ} \mathrm{C}$ & 28.42 & 2.93 & 16.33 & $3.19\left(10^{-6}\right)$ & 0.153 \\
\hline & $400^{\circ} \mathrm{C}$ & 24.35 & 2.10 & 5.964 & $9.03\left(10^{-6}\right)$ & 1.513 \\
\hline & $600{ }^{\circ} \mathrm{C}$ & 17.95 & 0.70 & 1.976 & $2.1\left(10^{-5}\right)$ & 16.70 \\
\hline
\end{tabular}




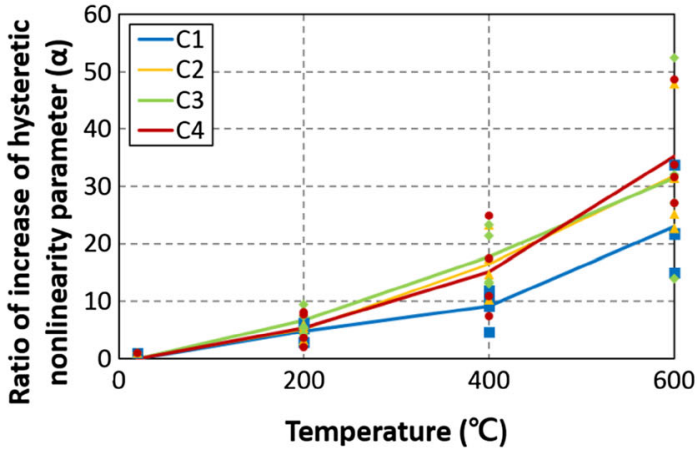

(a)

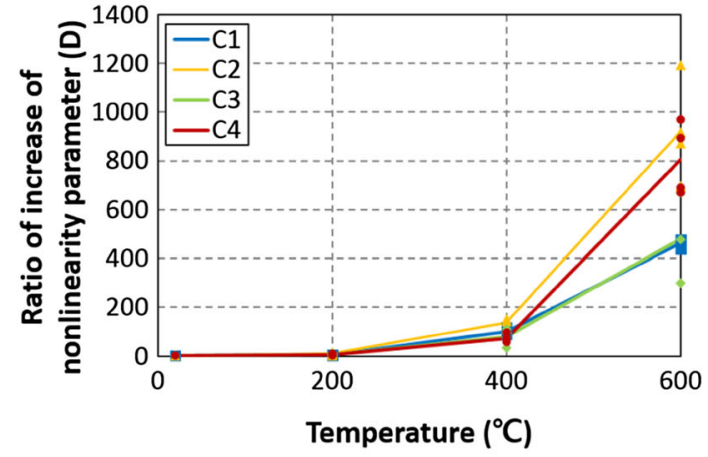

(b)

Fig. 6 Comparison of ratio of increase of the nonlinearity parameters at various temperatures. a Nonlinear resonance vibration method and $\mathbf{b}$ nonlinear modulation method.

The ratios of increase measured by both the methods are similar at approximately $200{ }^{\circ} \mathrm{C}$ for all the mix proportions; however, from 200 to $600{ }^{\circ} \mathrm{C}$, the ratio of increase measured by the modulation method is substantially higher than that measured by the resonance method. These trends are presented by comparing the results for all the mix proportions. The ratio of increase as measured by the nonlinear modulation method increases noticeably with temperature compared to that for the nonlinear resonance vibration method. Based on the comparison, it can be concluded that although the results of the nonlinear modulation method are more scattered than those of the nonlinear resonance vibration method, the nonlinear modulation method can better reflect fire damage (contact-type defects) at high heating temperatures than the nonlinear resonance vibration method.

In addition, a comparative analysis of compressive strength and splitting tensile strength was performed at various temperatures, as illustrated in Fig. 7. The trends of the ratios of decrease of the compressive strength and splitting tensile strength according to temperature appear to be highly similar regardless of mix proportions. The ratio of decrease of compressive strength reduces to approximately $30 \%$ at $200{ }^{\circ} \mathrm{C}$, which exhibits a noticeable variation from that of splitting tensile strength, except for the $\mathrm{C} 4 \mathrm{mix}$ proportion; however, the ratio of decrease of both the strength measurements are similar at $400{ }^{\circ} \mathrm{C}$ (approximately $60 \%$ of undamaged strength). On the other hand, the ratio of decrease of the splitting tensile strength reduces to approximately $20 \%$ of the undamaged strength, at $600{ }^{\circ} \mathrm{C}$; the degree of decrease is substantial when compared to the decrease in compressive strength (approximately 50\%). This implies that the splitting tensile strength marginally decreased compared to the compressive strength until $200{ }^{\circ} \mathrm{C}$ and then reduced remarkably at $600{ }^{\circ} \mathrm{C}$. While the compressive strength significantly decreased at a low temperature $\left(200^{\circ} \mathrm{C}\right)$, this decrease weakened with increasing temperature. It is determined that reactions in concrete, such as water evaporation in concrete and dehydration of the cement gel, are initiated up to $200{ }^{\circ} \mathrm{C}$ (Bazant and Kaplan 1996). The experimental results that exhibited a relatively significant reduction in compressive strength at a low heating temperature indicate that these reactions in concrete have a marginally higher effect on the compressive strength of the concrete material than on is splitting tensile strength. On the other hand, above $300{ }^{\circ} \mathrm{C}$, the cement paste undergoes morphological alterations, and the skeleton does not appear to be a continuous medium owing to its chemical dehydration caused by the continuously increasing temperature (Yim et al. 2012). These phenomena are likely to exert a higher influence on the reduction of splitting tensile strength than the reduction of compressive strength at a high heating temperature. Accordingly, the various ratios of decrease of mechanical strength can be used as a guideline to evaluate the heating temperature during a fire.

The experimental results of previous studies have revealed the relationship between the residual material properties and the parameters measured by a linear ultrasonic method (Yang et al. 2009) and that between the residual material properties and the nonlinearity parameters obtained from nonlinear ultrasonic methods (Park et al. 2015; Yim et al. 2014). The nonlinearity parameters measured by both the nonlinear methods were also correlated with the measured mechanical strength of the fire-damaged concrete: the nonlinearity parameter versus compressive strength; and the HNP versus tensile strength. As a departure from previous studies, this study presents new correlated relationships between the residual material properties and the measured nonlinearity parameters; this area is being addressed for the first time. Figure 8 presents the correlation between the ratio of decrease of the residual material properties, specifically compressive strength, splitting tensile strength, and static elastic modulus, and the ratio of increase of the nonlinearity parameters as measured by each of the nonlinear ultrasonic methods. These correlations are expressed after excluding the effect of mix proportions and exposure times. The dashed lines in Fig. 8 represent the relationships between the two variables (nonlinearity parameter and mechanical property) determined by regression analysis; the results exhibit a consistent tendency notwithstanding the omission of exposure time and mix proportion. The obtained 


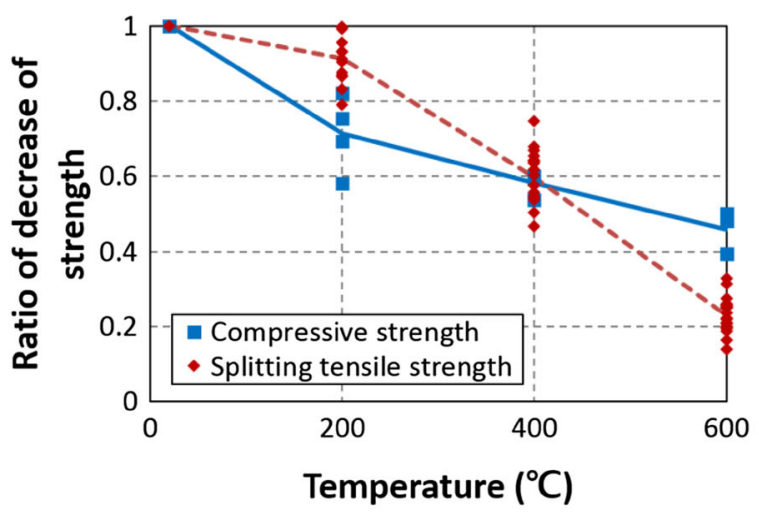

(a)

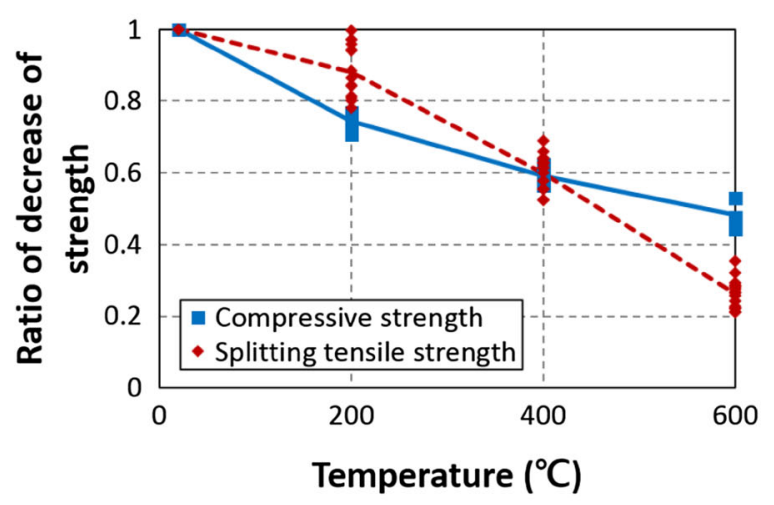

(c)

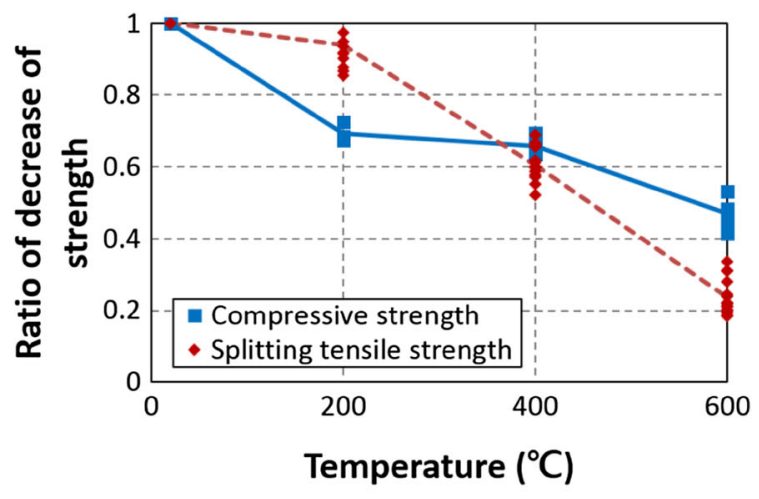

(b)

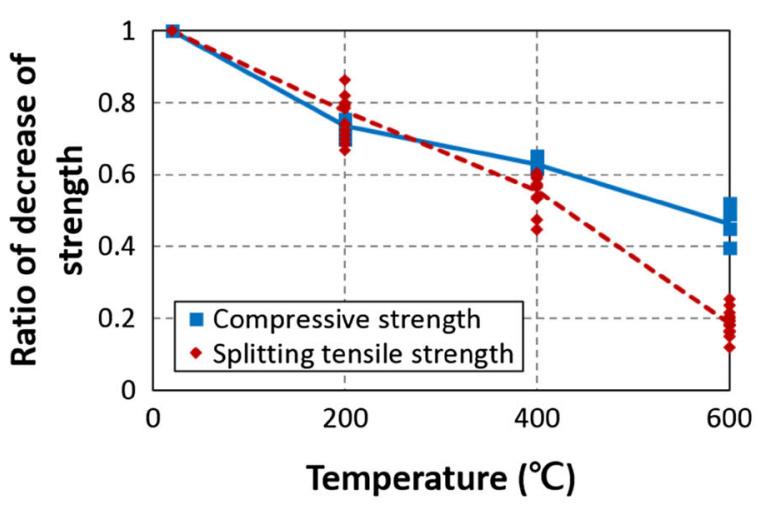

(d)

Fig. 7 Comparison of ratios of decrease of strength with temperature. a C1, b C2, c C3 and d C4.

regression results are expressed as Eqs. (6)-(8), which correspond to Fig. 8a-c, respectively:

$$
\begin{aligned}
& \frac{f_{c n}^{\prime}}{f_{c 0}^{\prime}}=0.93\left(\frac{\alpha_{n}}{\alpha_{0}}\right)^{-0.183} \\
& \frac{f_{t n}}{f_{t 0}}=1.34\left(\frac{D_{n}}{D_{0}}\right)^{-0.239} \\
& \frac{K_{c n}}{K_{c 0}}=1.35\left(\frac{\alpha_{n}}{\alpha_{0}}\right)^{-0.75}
\end{aligned}
$$

where the subscript $n$ corresponds to each experiment under various thermal conditions, and the subscript 0 corresponds to the experiment under the initial condition without damage. Moreover, $f_{c}^{\prime}, f_{t}, \alpha$, and $D$ are the compressive strength, splitting tensile strength, hysteretic nonlinearity parameter, and nonlinearity parameter, respectively.

These relationships for all the thermal damage cases are adequately described by a negative power function. In the initial phase, the ratios of the mechanical properties exhibited a remarkable decrease until the nonlinearity parameter ratios increased to 10 for the $\operatorname{HNP}(\alpha)$ and 200 for the nonlinearity parameter $(D)$ (approximately before $400{ }^{\circ} \mathrm{C}$ ); this is illustrated in Fig. 8. In the following phase, relatively widespread values of the nonlinearity parameters are apparent with marginal variations in the mechanical properties. Generally, this widespread section can be attributed to the fire-damage to the concrete when subjected to a temperature of approximately $600{ }^{\circ} \mathrm{C}$. This implies that the variations in the nonlinearity parameter ratios increase with temperature to a significantly higher degree than the variations in the strength ratios and static elastic modulus ratio. In addition, it can be observed that the compressive strength ratio, splitting tensile strength ratio, and static elastic modulus ratio converged to approximately $0.5,0.25$, and 0.1 , respectively. This implies that among the three parameters, the static elastic modulus is most sensitive to elevation in temperature, followed by the splitting tensile strength and compressive strength.

It may also be feasible to correlate the measured nonlinearity parameters with the mechanical properties regardless of the mix proportions used in this study. Therefore, the residual material properties of concrete induced by fire damage can be evaluated using these criteria under the assumption of the used mix proportions. For example, the residual compressive strength of fire-damaged concrete can be estimated by measuring the HNP via the nonlinear resonance vibration method using thin concrete disks.

An additional correlation study based on the ratios of decrease of the compressive strength and splitting tensile strength (measured mechanical strengths) of the fire-damaged concrete was performed, as illustrated in Fig. 9a. The ratio of compressive strength is proportional to that of the splitting tensile strength, and the optimized regression result is expressed as follows: 


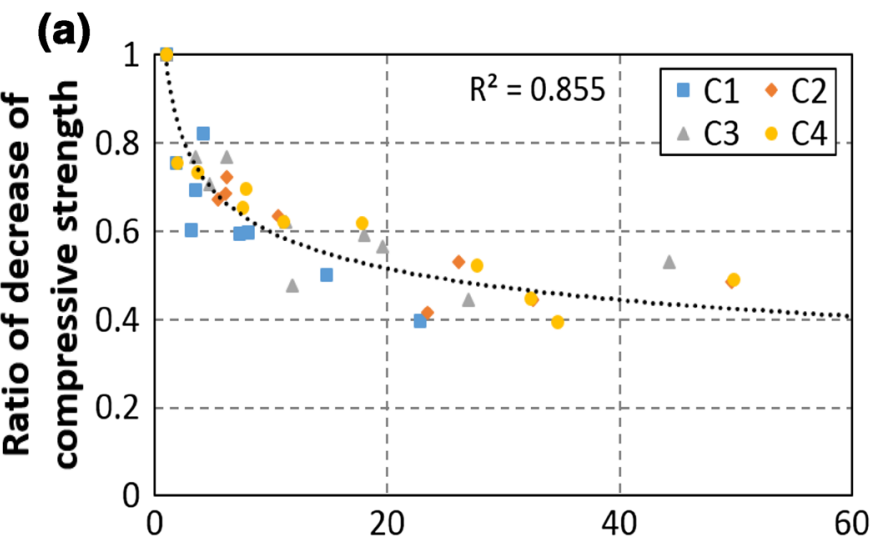

Ratio of increase of hysteretic nonlinearity parameter( $\alpha)$

(b)

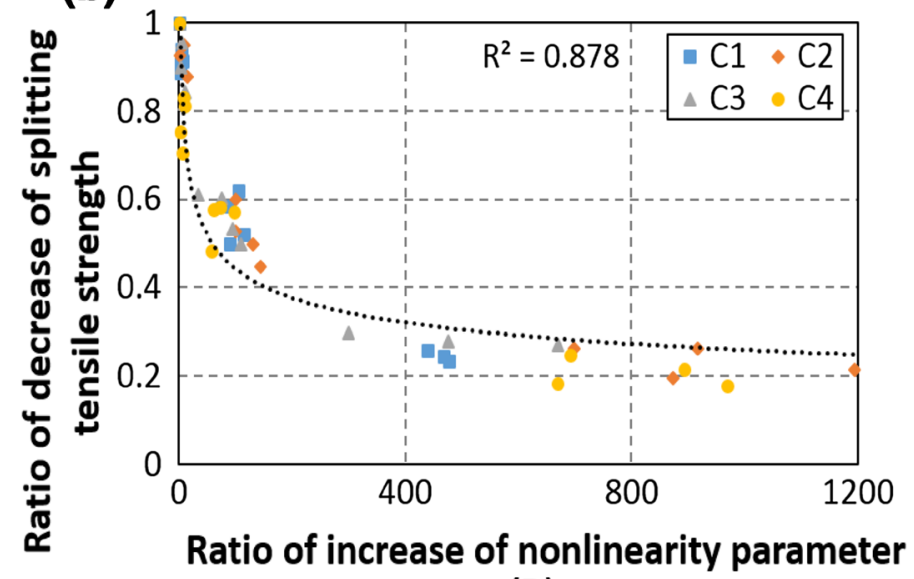

(D)

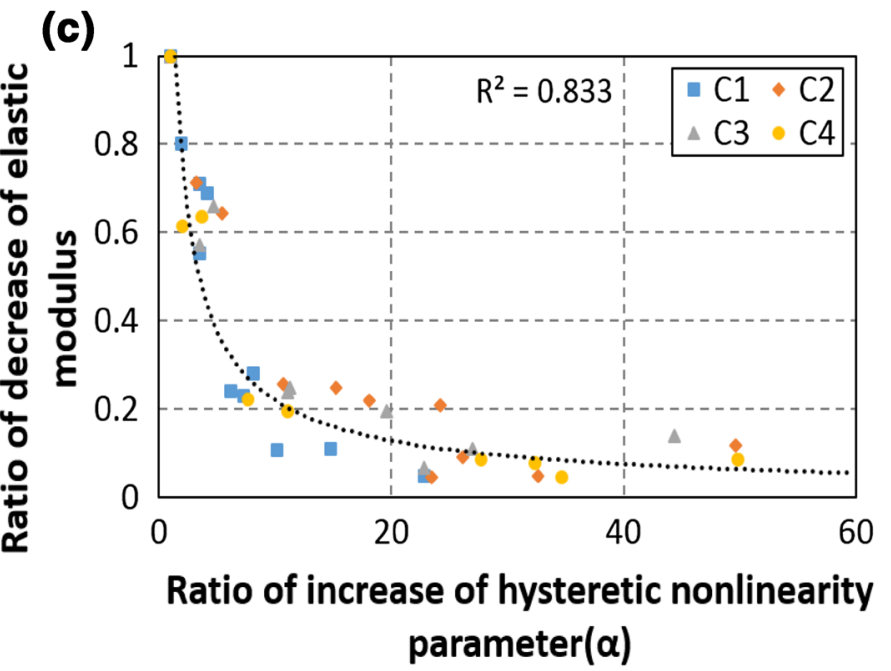

Fig. 8 Correlation between ratio of decrease of the residual material properties and ratio of increase of the nonlinearity parameters.

$$
\frac{f_{c n}^{\prime}}{f_{c 0}^{\prime}}=0.47\left(\frac{f_{t n}}{f_{t 0}}\right)+0.3532
$$

This study also investigated the effect of fire damage on the relationship between the residual compressive strength and splitting tensile strength of concrete (dashed line in Fig. 9b) through a comparison with the relationship collated and provided by Oluokun (1991), which has been tested by various investigators. Oluokun (1991) proposed the relationship between compressive strength and tensile strength solid line in Fig. 9b); however, it was obtained through regression analysis of measurements of undamaged concrete samples, and the relationship for fire-damaged concrete samples has not been reported yet. In the case of concrete with low fire damage, the relationship follows the trend of the result for undamaged concrete proposed by Oluokun 
(a)

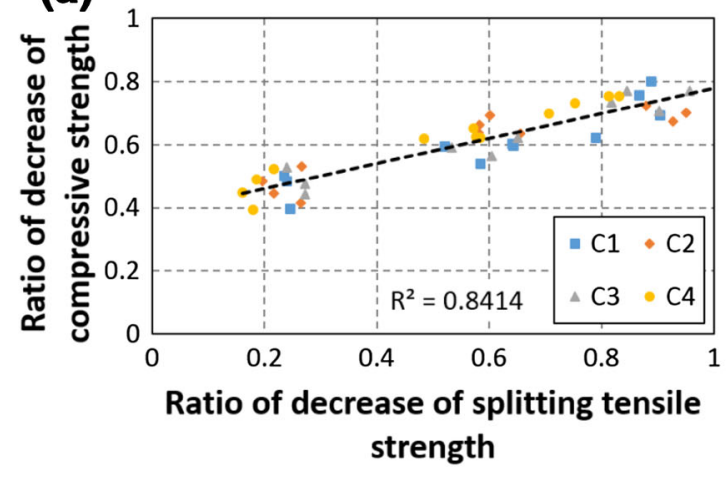

(b)

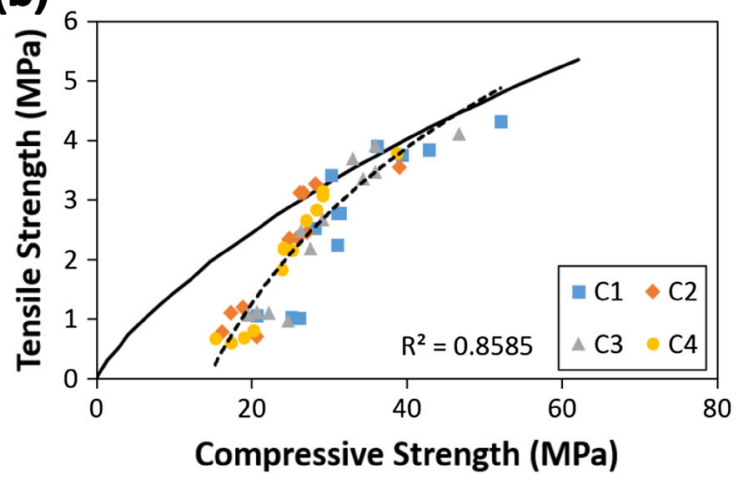

Fig. 9 Relationship between compressive strength and splitting tensile strength.

(1991). : On the other hand, as fire damage in the concrete sample increase, the fire-damaged relationship represented a steeper decline compared to undamaged relationship, which yields the following expression:

$$
f_{t n}=3.78 \ln \left(f_{c n}^{\prime}\right)-10.07
$$

The regressed relationships illustrate that fire damage degrades compressive strength more than it degrades tensile strength. Furthermore, based on Eqs. (9) and (10), the residual compressive strength of fire-damaged concrete can be estimated from the measured value of splitting tensile strength, and vice versa; thus, it is advantageous to select the more efficient method based on the circumstances.

\section{Conclusion}

This study involved an experimental analysis of the nonlinearity parameters measured by two nonlinear ultrasonic methods. For the evaluation of fire-damaged concrete, the nonlinearity parameter measured by the nonlinear modulation method provided higher sensitivity than that measured by the nonlinear resonance vibration method. The measured nonlinearity parameter can be affected by experimental conditions such as the sample size, the impact type and location of impact that is generated, wave reflection, and boundary condition of the sample. Accordingly, the experimental results of this study, rather than representing general relationships, can provide a guideline on the relationship between the mechanical properties of fire-damaged concrete and nonlinearity parameters measured by the two nondestructive methods. Based on the results of these experimental methods, correlated relationships were proposed to evaluate the residual properties of fire-damaged concrete using the measured nonlinearity parameter. From these relationships, the residual compressive strength, tensile strength, and static elastic modulus after being exposed to fire can be estimated using the measured nonlinearity parameters without considering the mix proportions of the concrete. In addition, the effect of fire damage on the mechanical strength of concrete was investigated by a comparison of undamaged relationships, and relationships determined through regression analysis were proposed for fire-damaged concrete.

\section{Acknowledgement}

This work was supported by the National Research Foundation of Korea (NRF) grant funded by the Korea government (MSIP) (No. 2015R1C1A1A01055474).

\section{Open Access}

This article is distributed under the terms of the Creative Commons Attribution 4.0 International License (http:// creativecommons.org/licenses/by/4.0/), which permits un restricted use, distribution, and reproduction in any medium, provided you give appropriate credit to the original author(s) and the source, provide a link to the Creative Commons license, and indicate if changes were made.

\section{References}

Al-Nimry, H. S., \& Ghanem, A. M. (2017). FRP confinement of heat-damaged circular RC columns. Int. J. Concr. Struct. Mater., 11, 115-133.

ASTM. (2001). ASTM C39: Standard test method for compressive strength of cylindrical concrete specimens. West Conshohocken, PA, USA: ASTM Int.

ASTM. (2011). ASTM C 496 M-11: Standard test method for splitting tensile strength of cylindrical concrete specimens. West Conshohocken, PA, USA: ASTM Int.

Bazant, Z. P., \& Kaplan, M. F. (1996). Concrete at high temperatures: material properties and mathematical models. Harlow: Longman.

Chaix, J. F., Garnier, V., \& Corneloup, G. (2003). Concrete damage evolution analysis by backscattered ultrasonic waves. NDT E Int., 36(7), 461-469.

Chang, Y. F., Chen, Y. H., Sheu, M. S., \& Yao, G. C. (2006). Residual stress-strain relationship for concrete after 
exposure to high temperatures. Cement and Concrete Research, 36(10), 1999-2005.

Chen, J., Jayapalan, A. R., Kim, J. Y., Kurtis, K. E., \& Jacobs, L. J. (2010). Rapid evaluation of alkali-silica reactivity of aggregates using a nonlinear resonance spectroscopy technique. Cement and Concrete Research, 40(6), 914-923.

Chen, J., Kim, J.-Y., Kurtis, K. E., \& Jacobs, L. J. (2011). Theoretical and experimental study of the nonlinear resonance vibration of cementitious materials with an application to damage characterization. Journal of the Acoustical Society of America, 130(5), 2728-2737.

Colombo, M., \& Felicetti, R. (2007). New NDT techniques for the assessment of fire-damaged concrete structures. Fire Safety Journal, 42(6), 461-472.

Dilek, U. (2007). Ultrasonic pulse velocity in nondestructive evaluation of low quality and damaged concrete and masonry construction. J. Perform. Constr. Facil., 21(5), 337-344.

Dilek, U., \& Leming, M. L. (2007). Comparison of pulse velocity and impact-echo findings to properties of thin disks from a fire damaged slab. J. Perform. Constr. Facil., 21(1), 13-21.

Donskoy, D., Sutin, A., \& Ekimov, A. (2001). Nonlinear acoustic interaction on contact interfaces and its use for nondestructive testing. NDT E Int., 34(4), 231-238.

Dos Santos, J. R., Branco, F. A., \& De Brito, J. (2002). Assessment of concrete structures subjected to fire-The FBTest. Mag. Concr. Res., 54(3), 203-208.

Epasto, G., Proverbio, E., \& Venturi, V. (2010). Evaluation of fire-damaged concrete using impact-echo method. Materials and Structures, 43(1-2), 235-245.

Ham, S., \& Oh, T. (2013). Effect of mixing and placing in hot weather on hardened concrete properties. Int. J. Concr. Struct. Mater., 7(2), 165-174.

Handoo, S. K. K., Agarwal, S. K. K., \& Agarwal, S. K. K. (2002). Physicochemical, mineralogical, and morphological characteristics of concrete exposed to elevated temperatures. Cement and Concrete Research, 32(7), 1009-1018.

Jhang, K. Y. (2009). Nonlinear ultrasonic techniques for nondestructive assessment of micro damage in material: A Review. Int. J. Precis. Eng. Manuf., 10(1), 123-135.

Kee, S. H., \& Nam, B. (2015). Automated surface wave measurements for evaluating the depth of surface-breaking cracks in concrete. Int. J. Concr. Struct. Mater., 9(3), 307-321.

Lee, J., Xi, Y., \& Willam, K. (2008). Properties of concrete after high-temperatures heating and cooling. ACI Materials Journal, 105(4), 334-341.

Leśnicki, K. J., Kim, J.-Y., Kurtis, K. E., \& Jacobs, L. J. (2011). Characterization of ASR damage in concrete using nonlinear impact resonance acoustic spectroscopy technique. NDT E International, 44(8), 721-727.

Li, H., \& Liu, G. (2016). Tensile properties of hybrid fiberreinforced reactive powder concrete after exposure to elevated temperatures. International Journal of Concrete Structures and Materials, 10(1), 29-37.

Oluokun, F. A. (1991). Prediction of concrete tensile strength from its compressive strength. Evaluation of existing relations for normal weight concrete. ACI Materials Journal, 88(3), 302-309.

Park, S.-J., Park, G.-K., Yim, H. J., \& Kwak, H.-G. (2015). Evaluation of residual tensile strength of fire-damaged concrete using a non-linear resonance vibration method. Magazine of Concrete Research, 67(5), 235-246.

Payan, C., Garnier, V., Moysan, J., \& Johnson, P. A. (2007). Applying nonlinear resonant ultrasound spectroscopy to improving thermal damage assessment in concrete. The Journal of the Acoustical Society of America, 121(4), EL125.

Payan, C., Garnier, V., \& Moysan, J. (2010). Potential of nonlinear ultrasonic indicators for nondestructive testing of concrete. Advances in Civil Engineering, 2010, 1-8.

Tufail, M., Shahzada, K., Gencturk, B., \& Wei, J. (2016). Effect of elevated temperature on mechanical properties of limestone, quartzite and granite concrete. International Journal of Concrete Structures and Materials., 11, 1-12.

Van Den Abeele, K. E. A. (1996). Elastic pulsed wave propagation in media with second- or higher-order nonlinearity. Part I. Theoretical framework. Journal of the Acoustical Society of America, 99(6), 3334-3345.

Van Den Abeele, K. E. A., Carmeliet, J., Ten Cate, J. A., \& Johnson, P. A. (2000a). Nonlinear elastic wave spectroscopy (NEWS) techniques to discern material damage, part I: Nonlinear wave modulation spectroscopy (NWMS). Research in Nondestructive Evaluation, 12(1), 17-30.

Van Den Abeele, K. E. A., Johnson, P. A., \& Sutin, A. (2000b). Nonlinear elastic wave spectroscopy (NEWS) techniques to discern material damage, part II: Single-Mode nonlinear resonance acoustic spectroscopy. Research in nondestructive evaluation, 12(1), 31-42.

Warnemuende, K., \& Wu, H. C. (2004). Actively modulated acoustic nondestructive evaluation of concrete. Cement and Concrete Research, 34(4), 563-570.

Yang, H., Lin, Y., Hsiao, C., \& Liu, J. (2009). Evaluating residual compressive strength of concrete at elevated temperatures using ultrasonic pulse velocity. Fire Safety Journal, 44(1), 121-130.

Yim, H. J., Kim, J. H., Park, S.-J., \& Kwak, H.-G. (2012). Characterization of thermally damaged concrete using a nonlinear ultrasonic method. Cement and Concrete Research, 42(11), 1438-1446.

Yim, H. J., Park, S.-J., Kim, J. H., \& Kwak, H.-G. (2014). Nonlinear ultrasonic method to evaluate residual mechanical properties of thermally damaged concrete. ACI Materials Journal, 111(4), 399-409.

Zaitsev, V., Nazarov, V., Gusev, V., \& Castagnede, B. (2006). Novel nonlinear-modulation acoustic technique for crack detection. NDT E Int., 39(3), 184-194. 